\title{
CLINICAL AND RADIOGRAPHIC EVALUATION OF IMMEDIATE NON-FUNCTIONAL LOADED IMPLANTS IN OSTEOPOROTIC PATIENTS
}

\author{
Mahmoud Mohsen El Arini* and Mohammed Omran Hamed ${ }^{* *}$
}

\begin{abstract}
Purpose: To compare success rate as well as difference of marginal bone loss around immediately placed non-functionally loaded implants in osteoporotic patients versus non-osteoporotic patients.

Material \& Methods: The present study was conducted on 12 patients, six of them were osteoporotic and the other six were normal healthy patients. Both groups underwent immediate post extraction implantation, with a total of 16 implants. Each patient was a candidate for single tooth replacement in the mandibular arch at the premolar area. СBCT was performed at the intervals of immediately after implant installation and 6 months postoperatively. This is to determine radiographic bone loss from initial surgery. Periotest was used to determine the implant mobility at the intervals of immediately after implant installation and 6 months postoperatively.

Results: The marginal bone level (flushed implant-bone crest to implant apex) baseline records at time of implant placement was used for all cases as a reference. And then, measurements were taken again after six months to detect the change in the marginal bone level for both groups. After 6 months, the mean marginal bone loss of the osteoporotic group was slightly higher than the normal group but yet not of significant difference. There was no statistically significant bone loss difference between the two groups either in coronal or sagittal sections.
\end{abstract}

Keywords IMPLANT, OSTEOPOROSIS, BONE LEVEL CHANGES

\section{INTRODUCTION}

Osteoporosis is considered a very common skeletal disease and is characterized by low bone density in human bone tissue ${ }^{1-2}$. Imbalances in bone remodeling can be a reason for constant decrease in bone volume and quantity ${ }^{3}$, and osteoporosis affects many individuals, mainly older women, worldwide ${ }^{4-5}$. Currently it is estimated that over 200 million people worldwide suffer from this disease ${ }^{6}$.

In osteoporosis, defective bone formation leads to a deterioration in the microstructure of trabecular bone and increases in cortical porosity, bone fragility,

* OMFS, Faculty of Oral and Dental Medicine, Future University, Cairo, Egypt

** OMFS, Faculty of Oral and Dental Medicine, Beni-Suef University, Beni-Suef, Egypt 
and the possibility of fracture. For this reason, the disease is of significance in implantology ${ }^{7-11}$.

Dental implants are frequently and effectively used in the rehabilitation of total and partial edentulism in most clinical scenarios and when immediate implant placement and loading could be achieved, it offers a considerable advantage over other treatment modalities such as the reduction of surgical interventions, the shortening of treatment period between surgery and prosthetic delivery without jeopardizing implant success rate; A solution for immediate restoration of any hopeless teeth; But does it fit all patients?

Patients may have risk factors that could affect treatment outcomes, and clinicians should modify treatment plans and expectations accordingly. Osteoporosis may be a risk factor for losing bone around dental implants, but the evidence is still not clear about what role it plays.

Previous studies showed that successful outcomes could be achieved when immediate implants was inserted in osteoporotic patients ${ }^{12-13}$.

Little is known about the interaction between osteoporotic bone and marginal bone loss around implants specifically implants that were immediately placed and non-functionally loaded and that is why this study was carried out.

The purpose of this study was to compare the success rate as well as differences of marginal bone loss around immediately placed non-functionally loaded implants in osteoporotic patients versus nonosteoporotic patients.

\section{MATERIAL AND METHODS}

12 Direct's Screw Plant ${ }^{\mathrm{TM}^{*}}$ implants of $11.5 \& 13$ $\mathrm{mm}$ length, $3.7 \& 4.7 \mathrm{~mm}$ diameter were inserted in the mandibular premolar region of 12 female patients with a mean age of 40 years planning for having dental implant for single tooth restoration.
All patients were selected from the out-patient clinic of Obestrics\& Gynecology department, Kasr El-Ainey hospital, Cairo University.

The selected patients were divided into 2 groups.

Group A: consisted of 6 female patients with established diagnosis of osteoporosis ( $\mathrm{T}$ score is less than -2.5) (osteoporotic group).

Group B: consisted of 6 normal postmenopausal female patients ( $\mathrm{T}$ score is more than -1) (control group)

Both groups were subjected to same protocol; preoperative evaluation, atraumatic extraction, immediate implantation, immediate non-functional loading, immediate postoperative evaluation (baseline), 3 months and 6 months postoperative evaluation.

\section{Inclusion criteria:}

Free from any systemic chronic debilitating disease that may contraindicate the surgery and/or implant placement.

Did not undergo radiotherapy and/or chemotherapy to the head and neck region.

Nonsmoker and nonalcoholic.

Have a non-restorable mandibular premolar.

Patients that fulfilled all the criteria of the study have accepted the treatment plan, were informed of all the surgical procedures and given a detailed explanation of the possibility of implant failure and consented for the procedure.

The study was conducted in accordance with the moral, ethical, regulatory, and scientific principles governing clinical research as set out in the Declaration of Helsinki (2013). All procedures and materials were approved by the local Ethics Committee of Future University, Egypt.

\footnotetext{
* implantdirect, USA. www.implantdirect.com
} 
TABLE (1): Demographic information of all investigated cases

\begin{tabular}{|c|c|c|c|c|}
\hline Case Number & Age & BMD Score & Missing Teeth & Inserted implants diameter (D) \& length (L) \\
\hline Case 1 & 45 years & $\begin{array}{l}-2.93 \\
\text { Osteoporotic }\end{array}$ & $\begin{array}{l}\text { LR 4, } \\
\text { LL4 }\end{array}$ & $\begin{array}{l}\text { D } 3.7 \text { L } 11.5 \\
\text { D } 3.7 \text { L } 13\end{array}$ \\
\hline Case 2 & 51 years & $\begin{array}{l}-2.66 \\
\text { Osteoporotic }\end{array}$ & LR4 & D $3.7 \mathrm{~L} 13$ \\
\hline Case 3 & 49 years & $\begin{array}{l}-2.51 \\
\text { Osteoporotic }\end{array}$ & LL5 & D 4.7 L 13 \\
\hline Case 4 & 50 years & $\begin{array}{l}-2.62 \\
\text { Osteoporotic }\end{array}$ & $\begin{array}{l}\text { LR 5, } \\
\text { LL5 }\end{array}$ & $\begin{array}{l}\mathrm{D} 4.7 \mathrm{~L} 13 \\
\mathrm{D} 4.7 \mathrm{~L} 13\end{array}$ \\
\hline Case 5 & 40 years & $\begin{array}{l}-0.81 \\
\text { Normal }\end{array}$ & LR5 & D 4.7 L 11.5 \\
\hline Case 6 & 38 years & $\begin{array}{l}-0.55 \\
\text { Normal }\end{array}$ & LL5 & D 4.7 L 13 \\
\hline Case 7 & 50 years & $\begin{array}{l}-0.43 \\
\text { Normal }\end{array}$ & LL5 & D 4.7 L 13 \\
\hline Case 8 & 35 years & $\begin{array}{l}-0.81 \\
\text { Normal }\end{array}$ & LL4 & D 4.7 L 13 \\
\hline Case 9 & 35 years & $\begin{array}{l}-0.73 \\
\text { Normal }\end{array}$ & LL5 & D 3.7 L 13 \\
\hline Case 10 & 38 years & $\begin{array}{l}-0.92 \\
\text { Normal }\end{array}$ & LL5 & D 4.7 L 11.5 \\
\hline
\end{tabular}

\section{Preoperative clinical evaluation:}

Examination of both hard and soft tissue through inspection and palpation.

Assessment of inter-arch space as well as the mesio-distal prosthetic space.

Evaluation of the mandibular premolar to be extracted confirming its non-restorability.

\section{Preoperative radiographic evaluation:}

A Cone beam computed tomography was performed for all cases as to exclude any hidden pathological lesion, obtain measurements from mental foramen, and assess bone quality and quantity.

Dual Energy X-ray Absorptiometry (DEXA) was used to measure bone mineral density (BMD) of the proximal femur of the lower limb for all cases by the device Norland, XR-46, v 3.9.6, USA for the diagnosis of osteoporosis.

\section{Surgical procedures:}

All the patients were treated with the same surgical technique consisting of atraumatic tooth extraction and simultaneous implant placement. In brief, a full-thickness flap was elevated, and two releasing incisions were performed, extending over the mucogingival junction. Tooth extractions were performed gently to minimize the trauma. After extraction, the socket was carefully curetted, and, subsequently, the implant bed was prepared according to the standard procedure with standard drills.

At the time of surgery, provisional non-functional crowns were fabricated and seated. 6 months later, permanent restorations were cemented.

Post-operative care: The patients were asked to perform the following measures: cold packs for the first 8 hours, soft diet for the first week, $1 \mathrm{~g}$ amoxi- 
cillin (or $300 \mathrm{mg}$ clindamycin) was prescribed 2 times per day for 5 days, brufen $400 \mathrm{mg}$ was prescribed twice per day for 5 days, warm chlorhexidine gluconate $0.1 \%$ mouth wash twice per day in the second post-operative day and was continued for two weeks, avoidance of the surgical site while brushing and eating, the sutures were removed after 7-10 days post-surgically, one week later the operation site was again checked to ensure complete soft tissue healing, and finally and the patients were seen monthly for prophylaxis and follow-up.

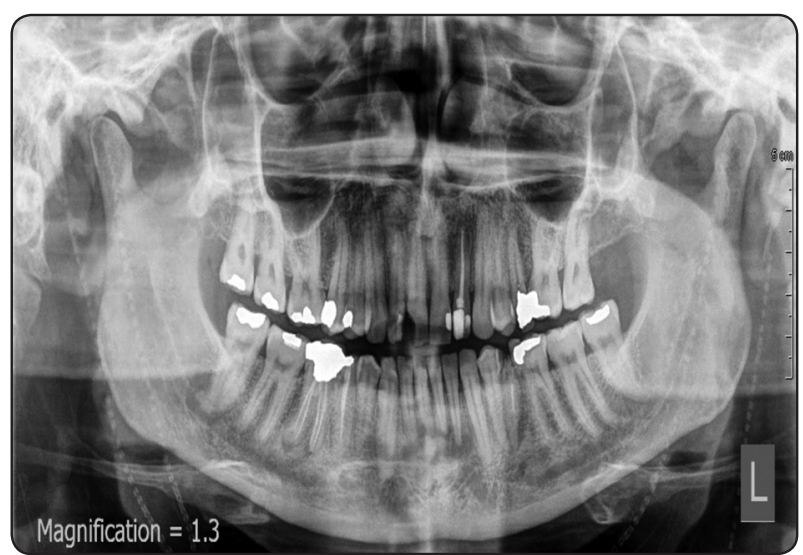

Fig. (1): Preoperative panoramic radiograph for case number 4 group A

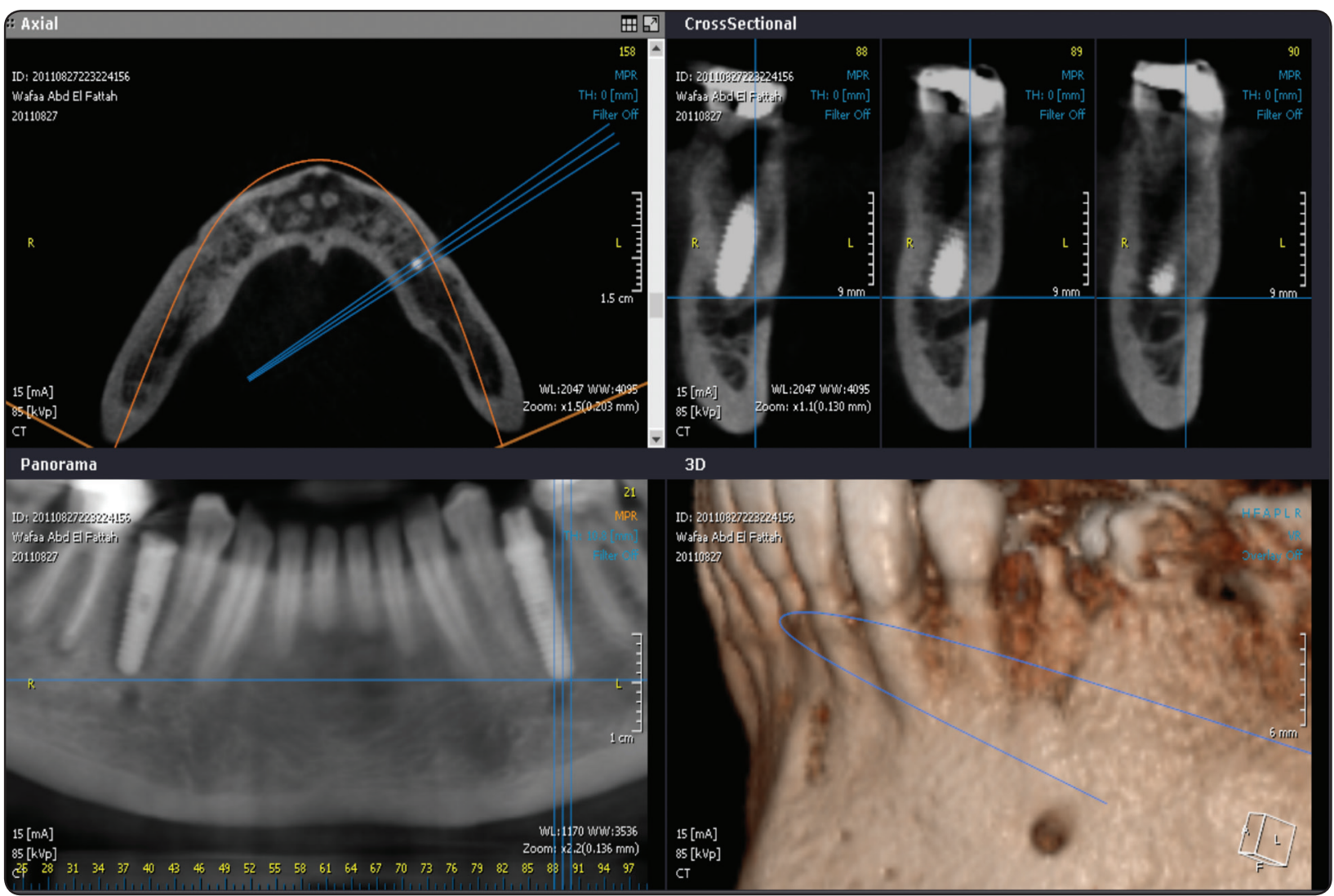

Fig. (2): Immediate postoperative cone beam radiograph for case number 4 group A 


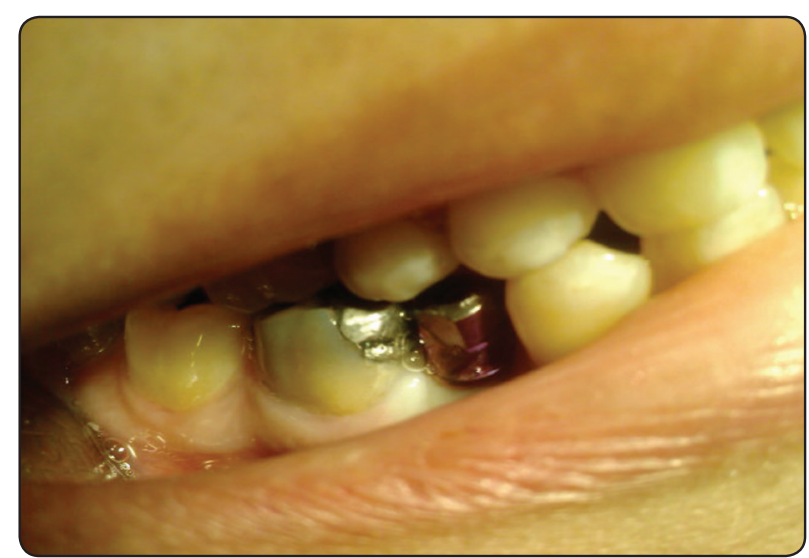

Fig. (3): Clinical photo showing immediate non-functional temporization of lower left second premolar (case number 4 group A)

\section{Postoperative clinical evaluation:}

Assessment of any subjective symptoms such as pain and/or dyasthesia.

Assessment of implant mobility 3 months postoperative and 6 months postoperative using Periotest $\mathbf{M}^{\circledR * *}$. The degree of implant mobility was evaluated according to Miller's classification enlisted in table 2.

TABLE (2): Miller's classification of implant mobility.

\begin{tabular}{|l|c|c|}
\hline Miller's original classification & $\begin{array}{c}\text { Mobility } \\
\text { (scores) }\end{array}$ & $\begin{array}{c}\text { Periotest } \\
\text { value }\end{array}$ \\
\hline No movement distinguishable & 0 & -8 to +9 \\
\hline $\begin{array}{l}\text { First distinguishable sign of } \\
\text { movement }\end{array}$ & 1 & $10-19$ \\
\hline $\begin{array}{l}\text { Implant deviates within } 1 \mathrm{~mm} \text { of its } \\
\text { normal position }\end{array}$ & 2 & $20-29$ \\
\hline $\begin{array}{l}\text { Mobility is easily noticeable, and the } \\
\text { implant moves more than } 1 \mathrm{~mm} \text { in } \\
\text { any direction }\end{array}$ & 3 & $30-50$ \\
\hline
\end{tabular}

\footnotetext{
** Medizintechnik Gulden e. k. Eschenweg 3. 64397 Modautal/Germany
}

\section{Postoperative radiographic evaluation:}

Cone beam computed tomography was taken immediate postoperative and considered baseline and after 6 months postoperative to detect differences in marginal bone level around the implant for all cases.

\section{Statistical analyses:}

Statistical analyses, including descriptive statistics for all clinical and radiographic parameters, were performed during the entire follow-up period. Implant clinical measurements were calculated by averaging the readings of each implant parameter for each patient, because the within patient variation was much lower than among patient variation. Subsequently, the means and medians were calculated among the means per patient at each study time point. The comparison within the group among the different time points was performed with dependent Student $t$ test (statistically significant at a level of $a=0.05$ ). The $P$ value was set at $<0.05$ with the Bonferroni corrections for multiple comparisons. All the data were analyzed using dedicated statistical software.

\section{RESULTS}

TABLE (3): The mean, standard deviation (SD) values and results of Mann-Whitney U test for comparison between bone loss values in the two groups

\begin{tabular}{|c|c|c|c|c|c|c|}
\hline \multirow{2}{*}{$\stackrel{0}{0}$} & \multirow{2}{*}{ Group } & \multicolumn{2}{|c|}{ Osteoporotic } & \multicolumn{2}{|c|}{ Normal } & \multirow{2}{*}{$P$-value } \\
\hline & & Mean & $\mathrm{SD}$ & Mean & SD & \\
\hline \multirow{2}{*}{ ن̃ } & Buccal & 0.32 & 0.07 & 0.22 & 0.11 & 0.082 \\
\hline & Lingual & 0.31 & 0.08 & 0.24 & 0.08 & 0.091 \\
\hline \multirow{2}{*}{ 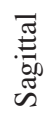 } & Mesial & 0.34 & 0.06 & 0.25 & 0.08 & 0.052 \\
\hline & Distal & 0.34 & 0.08 & 0.24 & 0.09 & 0.082 \\
\hline
\end{tabular}

$*$ : Significant at $P \leq 0.05$ 


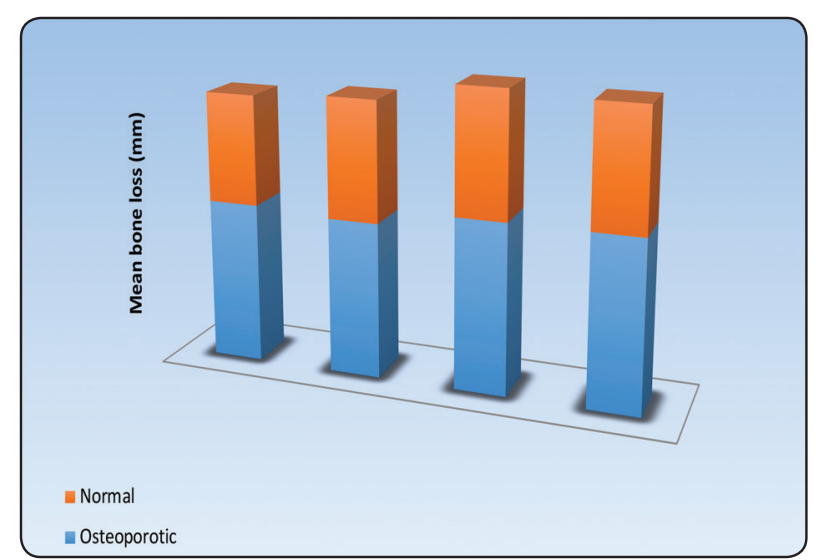

Fig. (4): Bar chart representing mean and standard deviation values for bone loss in the two groups

From table (3) and figure (4); it could be noticed that, implants placed in osteoporotic patients presented greater marginal bone loss than those implants placed in the normal group in a six-month period

TABLE (4): The mean, standard deviation (SD) values and results of Mann-Whitney U test for comparison between Periotest values in the two groups

\begin{tabular}{|l|c|c|c|c|c|}
\hline \multirow{2}{*}{ Group } & \multicolumn{2}{|c|}{ Osteoporotic } & \multicolumn{2}{|c|}{ Normal } & \multirow{2}{*}{ P-value } \\
\cline { 2 - 5 } & Mean & SD & Mean & SD & \\
\hline 3 months & -0.2 & 0.5 & -1.3 & 0.9 & 0.647 \\
\hline 6 months & -0.6 & 1.1 & -4.5 & 2.6 & 0.082 \\
\hline
\end{tabular}

*: Significant at $P \leq 0.05$

TABLE (5): The mean, standard deviation (SD) values and results of Wilcoxon signedrank test for the changes by time in Periotest values of each group

\begin{tabular}{|c|c|c|c|c|}
\hline \multirow{2}{*}{$\begin{array}{c}\text { Group } \\
\text { Time }\end{array}$} & \multicolumn{2}{|c|}{ Osteoporotic } & \multicolumn{2}{c|}{ Normal } \\
\cline { 2 - 5 } & Mean & SD & Mean & SD \\
\hline 3 months & -0.2 & 0.5 & -1.3 & 0.9 \\
\hline 6 months & -0.6 & 1.1 & -4.5 & 2.6 \\
\hline$P$-value & \multicolumn{2}{|c|}{0.175} & \multicolumn{2}{c|}{0.060} \\
\hline
\end{tabular}

*: Significant at $P \leq 0.05$

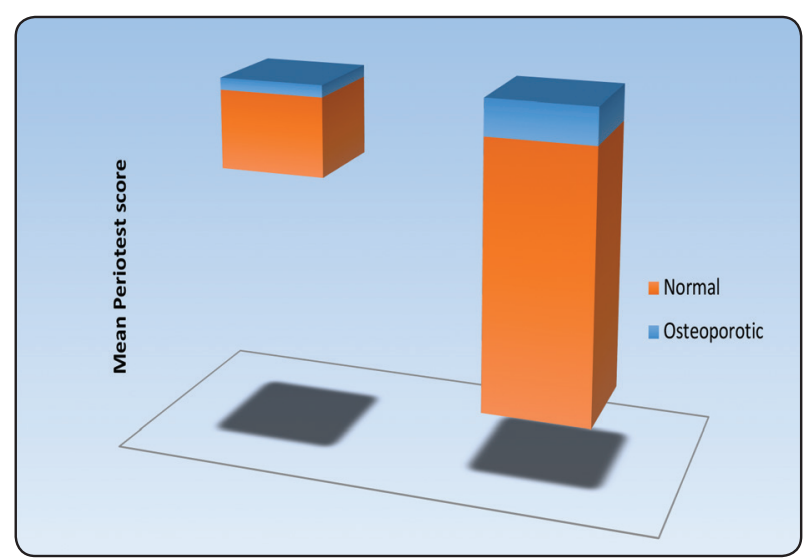

Fig. (5): Bar chart representing mean and standard deviation values for Periotest scores

From table (4) and table (5); it could be noticed that, after 6 months; normal group showed statistically significantly higher mean Periotest value than osteoportic group in a six-month period

TABLE (6): The frequencies, percentages, and results of Fisher's Exact test for comparison between success rate in the two groups

\begin{tabular}{|c|c|c|c|c|}
\hline \multicolumn{2}{|c|}{ Osteoporotic } & \multicolumn{2}{c|}{ Normal } & \multirow{2}{*}{$P$-value } \\
\cline { 1 - 3 } $\mathrm{N}$ & $\%$ & $\mathrm{~N}$ & $\%$ & \\
\hline $10 / 10$ & 100.0 & $10 / 10$ & 100.0 & 1.000 \\
\hline
\end{tabular}

*: Significant at $P \leq 0.05$

In this study, an average of $0.09 \mathrm{~mm}$ more marginal bone loss in osteoporotic patients than normal patients.

None of the implants in both groups have shown any significant readings of implant mobility using Periotest $\mathrm{M}$ which implies a successful osseointegration for all implants and a good clinical outcome

There was no statistically significant difference between success rate in the two groups, as all of the 12 implants of both groups was considered successful since there were no signs of pain or dyasthesia, all implants had have an accepted periotest values indicating good osseointegration 


\section{DISCUSSION}

Osteoporosis is a systemic condition with the potential of affecting implant therapy. It is of high incidence among the older population, which represents the greatest number of candidates for implant treatment ${ }^{14}$.

In this study, DEXA measurements were done on the proximal femur of the lower limb adjoining the hip and Central DEXA device was used for all cases for the diagnosis of osteoporosis because it is much more sensitive than peripheral devices. This was previously advocated by Taguchi et $\mathrm{al}^{15}$ and Thomsen et $\mathrm{al}^{16}$.

With the improvements in oral implantology resulting in improved prognosis and outcomes, the traditional protocol for implant dentistry has been constantly revised.

Recent advances include less treatment time through immediate placement of implants into fresh extraction sockets ${ }^{18}$ and by loading the implants immediately ${ }^{19}$. The need for fewer surgical interventions and minimized treatment time has led to more research regarding immediate postextraction implant placement and loading protocols.

A healing period of 4-6 months was initially adopted to ensure osseointegration of endosseous dental implants ${ }^{17}$.

The results of the present study could be explained by Degidi and Piattelli ${ }^{13}$, Calandriello et $\mathrm{al}^{20}$, Romanos et $\mathrm{al}^{21}$ and Ghanavati et $\mathrm{al}^{22}$ who found that immediately loaded implant"s micromovements can improve osseointegration and can dramatically increase the bone density. Also it was shown that immediate loads can increase the mineralization rate in bone-implant interface.

Osteoporotic bone is known of the imbalance in bone remodeling, yet it has proven to yield equivalent results to normal bone in oral implantology regarding immediate placement and loading ${ }^{19}$ but how much will be the affection of the amount of bone around the implants, that if early loss of crystal bone occurs, it could result in stagnation and bacterial proliferation on exposed implant threads which if left uncontrolled may result in further periimplant bone loss endangering the long-term implant success.

Preserving and monitoring crystal bone loss is important for the long-term maintenance of the implant and often used as an essential success criterion $^{23}$.

Albrektsson et $\mathrm{al}^{24}$ have reported an annual 0.1 to $0.2 \mathrm{~mm}$ of crystal bone loss after implant loading is normal occurring as a result of crestal bone remodeling. And the marginal crestal bone level change at the end of the first year should be less than $1.5 \mathrm{~mm}$.

In the study enrolled, the marginal bone level (flushed implant-bone crest to implant apex) baseline records at time of implant placement was used for all cases as a reference. And then, measurements were taken again after six months to detect the change in the marginal bone level for both groups. After 6 months, the mean marginal bone loss of the osteoporotic group was slightly higher than the normal group but yet not of significant difference. There was no statistically significant bone loss difference between the two groups either in coronal or sagittal sections.

Wagner et al, in an ongoing study have evaluated marginal bone loss in osteoporotic postmenopausal patients and have found an average of $0.78 \mathrm{~mm}$ more marginal bone loss in osteoporotic patients than normal patients ${ }^{25}$. In this study, an average of $0.09 \mathrm{~mm}$ more marginal bone loss in osteoporotic patients than normal patients. The difference may be attributed to small sample size and/or short follow up period.

Good primary stability serves to decrease the distortional strains in the newly regenerating tissues and to improve the chances of neo-osteogenesis at 
the interface; on the contrary, a poor stability of the implants has been shown to determine an important distortional strain with fibrous tissue formation at the interface ${ }^{26}$.

None of the implants in both groups have shown any significant readings of implant mobility using Periotest $\mathrm{M}$ which implies a successful osseointegration for all implants and a good clinical outcome which agrees with previous studies ${ }^{27}$.

After 3 months; there was no statistically significant difference between the two groups. While after 6 months; Group A (normal group) showed statistically significantly higher mean Periotest value than Group B (osteoportic group). There was no statistically significant change in mean Periotest values after 6 months in both groups. None of the implants in both groups have shown any signs of pain or dyasthesia in all cases in both groups.

Controlled studies without randomization showed that immediate loading is also possible for single-tooth gaps in the mandible without any effect on the implant survival rate ${ }^{28-29}$. For both the experimental and control groups, the implant survival rate was $100 \%$ up to a follow-up period of 6 months.

There was no statistically significant difference between success rate in the two groups, as all of the 12 implants of both groups was considered successful since there were no signs of pain or dyasthesia, all implants had have an accepted periotest values indicating good osseointegration, and all implants have received a functional prosthetic crowns after the temporary composit crowns that was in the 6 months study period.

In conclusion, dental implants inserted immediately following extraction in osteoporotic patients do present success rates nearly equivalent to those implants placed in normal patients. None of the implants in both groups have shown any clinical signs of implant failures. However, implants placed in osteoporotic patients presented greater marginal bone loss than those implants placed in the normal group in a six-months period but the change was insignificant. These results should be considered but further prospective studies are needed with greater sample size and longer follow-up periods.

\section{REFRENCES}

1. Siebert T, Jurkovic R, Statelova D, Strecha J. Immediate implant placement in a patient with osteoporosis undergoing bisphosphonate therapy: 1-year preliminary prospective study. J Oral Implantol. 2015; 41. Spec No: 360-365.

2. Temmerman A, Rasmusson L, Kubler A, Thor A, Quirynen M. An open, prospective, non-randomized, controlled, multicentre study to evaluate the clinical outcome of implant treatment in women over 60 years of age with osteoporosis/osteopenia: 1-year results. Clin Oral Implants Res 2017; 28:95-102.

3. Dvorak G, Arnhart C, Heuberer S, Huber CD, Watzek G, Gruber R. Peri-implantitis and late implant failures in postmenopausal women: a cross-sectional study. J Clin Periodontol 2011; 38:950-5.

4. Mulligan R, Sobel S. Osteoporosis: diagnostic testing, interpretation, and correlations with oral health - implications for de0ntistry. Dent Clin North Am 2005; 49:463-84.

5. Erdogan O, Shafer DM, Taxel P, Freilich MA. A review of the association between osteopo-rosis and alveolar ridge augmentation. Oral Surg Oral Med Oral Pathol Oral Radiol Endod 2007; 738:e1-3.

6. Cooper C, Campion G, Melton LJ 3rd. Hip fractures in the elderly: a world-wide projection. Osteoporos Int. 1992 Nov; 2(6):285-9

7. Alghamdi HS, Jansen JA. Bone regeneration associated with nontherapeutic and therapeutic surface coatings for dental implants in osteoporosis. Tissue Eng Part B Rev 2013;19:233-53.

8. Famili P, Zavoral JM. Low skeletal bone mineral density does not affect dental implants. J Oral Implantol 2015; 41:550-3.

9. Al-Sabbagh M, Robinson FG, Romanos G, Thomas MV. Osteoporosis and bisphosphonate-related osteonecrosis in a dental school implant patient population. Implant Dent 2015; 24:328-32. 
10. Becker W, Hujoel PP, Becker BE, Willing- ham H. Osteoporosis and implant failure: an exploratory case-control study. J Periodontol 2000;71:625-31.

11. Beppu K, Kido H, Watazu A, Teraoka K, Matsuura M. Peri-implant bone density in senile osteoporosis - changes from implant placement to osseointegration. Clin Implant Dent Relat Res 2013; 15:217-26.).

12. Tomas S, Richard J, Dagmar S, Juraj S. Immediate Implant Placement in a Patient with Osteoporosis Undergoing Bisphosphonate Therapy: 1-Year Preliminary Prospective Study. J oral implantology.2015; 41.

13. Degidi M, Piatteli A. Immediately loaded bar-connected implants with an anodized surface inserted in the anterior mandible in a patient with osteoporosis: a case report with a 12-month follow-up. Clin Implant Dent Relat Res 5(4):269-72,2003.

14. Lerner UH. Bone remodeling in postmenopausal osteoporosis. J Dent Res 85:584-595, 2006.

15. Taguchi A, Tanimoto K, Suei Y,Otani K, Wada T. Relationship between the mandibular and lumbar vertebral bone mineral density at different postmenopausal stages. Dentomaxillofac Radiol 25:130-135, 1996.

16. Thomsen JS, Ebbesen EN, Moseklde L. Static histomorphometry of human iliac crest and vertebral trabecular bone: a comparative study. Bone 30:267-274, 2002.

17. P.I. Brånemark, B.O. Hansson, R. Adell, U. Breine, J. Lindström, O. Hallén, A. Ohman. Osseointegrated implants in the treatment of the edentulous jaw. Experience from a 10year period. Scandinavian Journal of Plastic and Reconstructive Surgery. Supplementum, 16: 1-132, 1977.

18. B.R. Chrcanovic, M.D. Martins, A. Wennerberg. Immediate placement of implants into infected sites: a systematic review. Clinical Implant Dentistry and Related Research (2013).

19. P.O. Östman, A. Wennerberg, A. Ekestubbe, T. Albrektsson. Immediate Occlusal Loading of NanoTite ${ }^{\mathrm{TM}}$ Tapered Implants: a Prospective 1-Year Clinical and Radiographic Study. Clinical Implant Dentistry and Related Research, 15: 809-818, 2013.

20. Calandriello R, Tomatis M, Vallone R, Rangert B, Gottlow J. Immediate occlusal loading of single lower molars using
Brånemark System Wide-Platform TiUnite implants: an interim report of a prospective open-ended clinical multicenter study. ClinImplantDent Relat Res 5: 74-80, 2003.

21. Romanos GE,Testori T, Degidi M,PiattelliA.Histologic and histomorphometric findings from retrieved,immediately occlusally loaded implants in humans. J Periodontol 76 : 1823-1832, 2005.

22. Ghanavati F, Shayegh SS, Rahimi H, Sharifi D, Khalesseh $\mathrm{N}$. The effects of loading time on osseointegration and new bone formation around dental implants: a histologic and histomorphometric study in dogs. J Periodontol 77: 17011707, 2006.

23. A. Mombelli, N.P. Lang. The diagnosis and treatment of peri-implantitis. Periodontol 2000, 63-76 (17) 1998.

24. T. Albrektsson, G. Zarb, P. Worthington, A.R. Eriksson. The long-term efficacy of currently used dental implants: a review and proposed criteria of success. Int J Oral Maxillofac Implants, 1 11-25, 1986.

25. Wagner F, Schuder K, Hof M, Heubere S, Seemann R, Dvorak G. Osteoporosis may result in small increase in marginal bone loss around dental implants in osteoporotic women. Clin Implant Dent Relat Res, 8, 2017.

26. Carter, D. R. and N. J. Giori. Effect of mechanical stress on tissue differentiation in the bony implant bed. In: Davies JE, ed. The Bone-Biomaterial Interface. Toronto, Ontario, Canada: University of Toronto Press; 367-379, 1991.

27. Degidi M, Piatteli A. Immediately loaded bar-connected implants with an anodized surface inserted in the anterior mandible in a patient with osteoporosis. A case report with a 12 month follow-up period. Clin Implant Dent Relat Res, 5 (4), 269-72, 2003.

28. Cannizzaro G, Leone M: Restoration of partially edentulous patients using dental implants with a microtextured surface: a prospective comparison of delayed and immediate full occlusal loading. Int J Oral Maxillofac Implants;18:512-522, 2003.

29. Ericsson I, Nilson H, Lindh $\mathrm{T}$ et al.: Immediate functional loading of Brånemark single tooth implants. An 18 months' clinical pilot follow-up study. Clin Oral Implants Res;11:26-33, 2000. 